\title{
RETRACTED ARTICLE: Peroxidase Gene-Based Estimation of Genetic Relationships and Population Structure Among Wild Pistacia Species Populations
}

\author{
Setareh Mirzavand ${ }^{1} \cdot K_{\text {Karim }}$ Sorkheh $^{1}$. \\ Mohammad Reza Siahpoosh ${ }^{1}$
}

Received: 9 July 2016/Accepted: 28 September 2016/Published online: 4 October 2016

(C) Springer Science+Business Media New York 2016

This article has been retracted by the Publisher in agreement with the Editor-inChief, because it contains portions of writings on the same topic already published and without sufficient attribution to these earlier works being given. The principal authors of the paper acknowledged that text from background sources was mistakenly used in this article without proper reference to the original source. Upon investigation carried out according to the Committee on Publication Ethics' guidelines, it has been found that the authors have duplicated or rephrased substantial parts from other articles of which the main sources are the following:

Gulsen O, Kaymak S, Ozongun S, Uzun A (2010) Genetic analysis of Turkish apple germplasm using peroxidase gene-based markers. Scientia Horticulturae 125:368-373.

Ocala N, Akbuluta M, Gulsen O, Yetisir H, Solmaz I, Sari N (2014) Genetic diversity, population structure and linkage disequilibrium among watermelons based on peroxidase gene markers. Scientia Horticulturae 176:151-161.

In a commitment to scientific integrity we decided to withdraw the article.

The online version of this article contains the full text of the retracted article as electronic supplementary material.

Electronic supplementary material The online version of this article (doi:10.1007/s10528-016-9776-3) contains supplementary material, which is available to authorized users.

Karim Sorkheh

karimsorkheh@gmail.com

1 Department of Agronomy and Plant Breeding, Faculty of Agriculture, Shahid Chamran University of Ahvaz, Ahvaz, P. O. Box 61355/144, Iran 